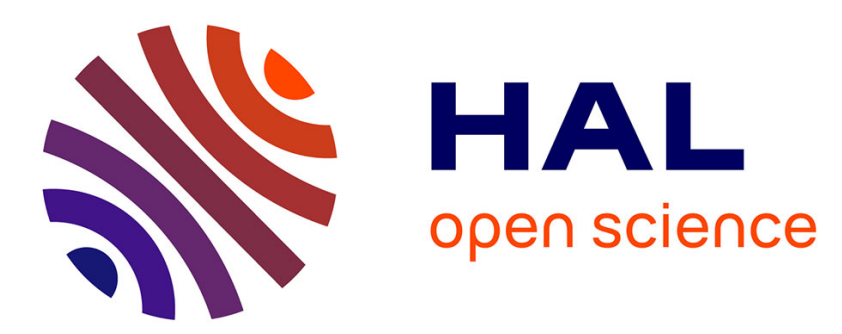

\title{
Inter-cluster relations in a coopetition context: the case of Inno'vin
}

Julien Cusin, Elodie Loubaresse

\section{To cite this version:}

Julien Cusin, Elodie Loubaresse. Inter-cluster relations in a coopetition context: the case of Inno'vin. Journal of Small Business \& Entrepreneurship, 2017, 30 (1), pp.27-52. 10.1080/08276331.2017.1356158. hal-03239109

\section{HAL Id: hal-03239109 \\ https://hal.science/hal-03239109}

Submitted on 27 May 2021

HAL is a multi-disciplinary open access archive for the deposit and dissemination of scientific research documents, whether they are published or not. The documents may come from teaching and research institutions in France or abroad, or from public or private research centers.
L'archive ouverte pluridisciplinaire HAL, est destinée au dépôt et à la diffusion de documents scientifiques de niveau recherche, publiés ou non, émanant des établissements d'enseignement et de recherche français ou étrangers, des laboratoires publics ou privés. 


\title{
INTER-CLUSTER RELATIONS IN A COOPETITION CONTEXT: THE CASE OF INNO'VIN
}

\begin{abstract}
While interclustering corresponds to a specific case of inter-organisational relations, its coopetitive and asymmetric potential has rarely been investigated. Here, we examine the challenges in developing a productive coopetitive inter-cluster relationship in a context of asymmetry, and the trust-generating mechanisms needed to overcome these challenges. The case of the French cluster, Inno'vin, gives us some interesting insights into the issue. With four data collection phases conducted over an eight-year period, we compared the relations between Inno'vin and two other clusters located in the same or a nearby geographical area and positioned in similar fields. Our paper highlights the importance of competition in the context of interclustering and identifies the main challenges of inter-cluster coopetition, while emphasizing the role of asymmetry. Moreover, we extend the existing literature on trustgenerating mechanisms in the specific context of asymmetric interclustering.
\end{abstract}

Key Words

Interclustering - coopetition - wine sector - asymmetric relations

\section{JULIEN CUSIN}

Julien Cusin is currently associate professor at IAE Bordeaux (University of Bordeaux), and is a member of the IRGO research laboratory. Most of his works deal with failure management.

\section{ELODIE LOUBARESSE ${ }^{1}$}

Elodie Loubaresse is currently associate professor at Paris-Sud University, and is a member of the RITM research center. Most of her work deal with inter-organizational relations.

\section{Introduction}

The traditional view of interclustering reflects the implicit postulate of the cluster literature, according to which such relations create value for clusters (Bathelt et al., 2004). From this perspective, interclustering is a synonym for cooperation. In fact, the concept of competition is absent in studies on inter-cluster relations, while intra-cluster competition is widely present in the literature (Dana and Granata, 2013; Mesquita, 2007; Ingstrup and

\footnotetext{
${ }^{1}$ Corresponding author
} 
Damgaard, 2013). However, areas of friction may well arise in the specific context of interclustering, particularly between members, in collaborative projects or with respect to funding, when the cluster initiative (Lundequist and Power, 2002; Teigland and Lindqvist, 2007) is organized by an association. This friction inevitably endangers the win-win logic in the event of cooperation. Consequently, we believe that it is useful to study interclustering in a coopetitive context, especially as much of the studies on coopetition analyses dyadic relations (Bengtsson and Kock, 2000) in line with the literature on inter-organisational relations (Hamel et al., 1989). Moreover, from the moment we introduce the concept of competition in the context of interclustering, it seems logical to also think in terms of asymmetry - that is in terms of balance of power - between the entities. This is a highly traditional approach in the literature on alliances (Casciaro and Piskorski, 2005; Chen and Chen, 2002; Wang, 2011) which are the most frequent examples of coexistence between cooperation and competition (Dussauge and Garrette, 1999; Hamel et al., 1999).

The dynamics of partner-competitor relations have yet to be explored in-depth in the management literature. As such, studying coopetition between inter-organisational networks in the specific case of inter-cluster relations offers a new framework in which to analyse coopetition that has seldom been investigated (Peng and Bourne, 2009). We believe that it constitutes an interesting line of research, especially when we look into the sources and management of tension (Bengtsson and Kock, 2014; Fernandez et al., 2014) in relations between two close clusters which need to trust one another (Bathelt and Li, 2014; Schüssler et al., 2013). In particular, following Thomason and Kiernan (2013), who highlight several determinants of successful coopetition (trust, commitment and mutual benefit), it can be instructive to investigate how asymmetric inter-cluster relations can be managed so as to balance cooperation and competition without endangering coopetition (Bengtsson and Kock, 2014). Our study therefore addresses the following question: "What are the challenges to 
developing a productive coopetitive inter-cluster relationship, in a context of asymmetry, and what are the trust-generating mechanisms needed to overcome these challenges?"

To answer this question, we conducted a qualitative study of two asymmetric and coopetitive dyadic inter-cluster relations between French wine and vine (w\&v) clusters, to which many SMEs adhere because of the highly fragmented nature of this industry. More specifically, on the one hand, we analysed the relations between Inno'vin (a wine cluster in the Nouvelle-Aquitaine region around Bordeaux) and MPA (an agro-industrial 'competitiveness cluster' $^{2}$ from both the Occitanie region around Toulouse and the Nouvelle-Aquitaine region, partially dedicated to w\&v). Second, we analysed the relationship between Inno'vin and LR (a CC located in the Occitanie region around Montpellier, partially dedicated to w\&v). ${ }^{3}$ Using the methodology developed by Gioia et al. (2013), our paper highlights the importance of competition in the context of interclustering and identifies the main challenges of inter-cluster coopetition, while emphasizing the role of asymmetry. In addition, we extend the existing literature on trust-generating mechanisms in the specific context of asymmetric interclustering.

\section{Liter ature review}

\section{Interclustering and alliance relations}

A growing number of studies have explored the challenges faced by clusters ${ }^{4}$ that extend beyond their geographical or industrial borders. Bathelt et al. (2004), for instance, studied the global pipelines linking clusters at international level and facilitating knowledge creation. Intercluster relations demand a high degree of trust, time to develop, consensus over goals, and cognitive, cultural and institutional proximity (Bathelt and Li, 2014; Schüssler et al., 2013).

\footnotetext{
${ }^{2}$ A competitiveness cluster (CC) is a cluster accredited by the French government that "groups small and large firms, research centers and training institutions in a well-defined territory and a targeted field" (www.competitivité.gouv.fr). It is partially publicly funded.

${ }^{3}$ Nouvelle-Aquitaine and Occitanie are two neighboring regions in France (from a total of 13 regions).

${ }^{4}$ A cluster is a geographical concentration of firms, specialised suppliers, service providers and institutions in a specific field, both competing and cooperating (Porter, 1998).
} 
Clusters can thus be embedded in larger networks of global relations to reduce their technological lock-in (Crespo et al., 2014), such networks being emergent or more deliberate, and often involving cluster actors (Schüssler et al., 2013).

The few studies on inter-cluster relations have investigated their determinants (Amisse et al., 2011) or impact in terms of knowledge creation (Bathelt et al., 2004). Apart from Peng and Bourne (2009), most studies have focused on global relations (Bathelt and Li, 2014; Crespo et al., 2014). Only a few authors have investigated inter-cluster relations within a common territory, mostly in terms of complementarity (Porter, 1998). These contributions share a positive and normative vision of interclustering, rarely questioning the asymmetric and coopetitive dimensions.

Inter-cluster relations may be considered as a specific type of inter-organisational relationship. Whether dyadic or not, they can thus be analysed in the numerous papers devoted to strategic alliances (Doz and Hamel, 1998; Dussauge and Garrette, 1999; Das and Teng, 2001) that provide us with a useful theoretical framework to examine these relations, especially when they are dyadic and potentially unbalanced. Asymmetric relations between partners in dyadic alliances have been widely studied, in particular in terms of power and dependence (Casciaro and Piskorski, 2005; Wang, 2011), size and reputation of the partners, level of development of the home country, or investment and gain (Chen and Chen, 2002).

Nevertheless, this approach to asymmetries does not take into consideration the fact that partners are embedded in a network of actors (Gulati, 1998), which can potentially influence their actions (Granovetter, 1985), and more precisely the relations they nurture with others. Gulati (1998), following Granovetter (1992), distinguishes two embeddedness mechanisms in alliance networks: relational and structural embeddedness. On the one hand, "relational embeddedness or cohesion perspectives on networks stress the role of direct cohesive ties as a mechanism for gaining fine-grained information. Actors who share direct connections with 
each other are likely to possess more common information and knowledge of each other." (Gulati, 1998, p. 296). On the other hand, "structural embeddedness or positional perspectives on networks go beyond the immediate ties of firms and emphasize the informational value of the structural position these partners occupy in the network. Information travels not only through proximate ties in networks, but through the structure of the network itself." (Gulati, 1998, p. 296).

At the same time, given the existence of asymmetries, the literature also investigates the management and control of interorganisational relations. The coopetition framework, which highlights their coopetitive dimension, can complement our analysis of dyadic relations management.

\section{Management of asymmetric and coopetitive relations}

Management of asymmetric relations

Asymmetric relations are problematic, especially for a partner that perceives and associates them with risk due to uncertainty regarding the other partner's behaviour (Das and Teng, 2001). The literature on the management and control of such asymmetric relations tends to adopt one of two main approaches (Donada and Nogatchewsky, 2006):

- The transactional approach provides insights into 'hold-up' situations due to specific assets. Partners suffering from asymmetry need to work on safeguards to strengthen their irreplaceability, or else should try to make the change of partner costly. In this case, formal mechanisms such as contracts may be useful.

- The relational approach takes the temporal dynamics of the relations into account (Larson, 1992; Ring and van de Ven, 1994). Partners within an alliance test their cooperation on nonrisky operations and decide then whether to increase their commitment. Such cooperation relies on proximity, relational norms and trust. This trust can be generated simply by the 
characteristics of a person (characteristic-based trust), by the positive outcomes of previous exchanges (process-based trust) or by the influence of a trusted superior authority (institutionalbased trust) (Zucker, 1986). Trust dissuades the least dependent partners from being opportunist or ending the relationship. The mechanisms at play here are informal (Larson, 1992; Cannatelli and Antoldi, 2012; Fink et al., 2010).

The trade-off between formal and informal mechanisms as modes of alliance control can be explained by the extent of asymmetry between partners (Delerue, 2010; Vidot-Delerue and Simon, 2005). Control is likely to be formal in situations of high perceived asymmetry (and informal otherwise). Nonetheless, it is possible for organisations to adopt a combination of transactional and relational approaches (Donada and Nogatchewsky, 2006).

By definition, organisations involved in an alliance are engaged in relations based simultaneously on competition and cooperation (Hamel et al., 1989), that is coopetition (Bengtsson and Kock, 2000). This related theoretical field shares a concern for the management or regulation of such relations, giving additional insights into inter-cluster relations.

\section{Coopetition management}

Coopetition appears when competitive and cooperative relations exist between organisations. Thus, the concept offers a complementary analytical framework for inter-cluster relations. Bengtsson and Kock (2014: 180) propose the following definition: "coopetition is a paradoxical relationship between two or more actors, regardless of whether they are in a horizontal or vertical relationship, simultaneously involved in cooperative and competitive interactions". Coopetition needs to be described according to not one but two continuums, in other words, cooperation and competition. These should not be seen as extremes of a same continuum in which one dominates the other. One of the challenges is thus to understand the balance between cooperation and competition. A lack of balance between the two can harm the 
dynamics of coopetition, especially in the event of over-embeddedness, alienation, confrontation or collusion (Bengtsson et al., 2010). This is all the more regrettable in that coopetition is meant to "enlarge the pie" and create a win-win situation for the partners/competitors (Brandenburger and Nalebuff, 1996; Dana and Granata, 2013).

The main contexts studied in this field are strategic alliances and inter-organisational networks. Only a few authors have examined coopetition relations between inter-organisational networks (Bengtsson and Kock, 2014). Peng and Bourne (2009) investigated the question, concluding that coopetition between networks is possible under three conditions: when their resources are distinct but complementary, when the cooperation and competition fields are separate, and when the network structures are distinct but compatible. They also stress the role of related network management mechanisms and activities.

Managing tension within relationships appears to be a central issue (Bengtsson and Kock, 2014; Fernandez et al., 2014). According to Fernandez et al. (2014), the management modes of this tension are separation (Bengtsson and Kock, 2000) and integration (Chen, 2008). Recent studies have looked at coopetition regulations (Assens and Coleno, 2014; Fernandez et al., 2014), examining different regulation mechanisms, whether formal or informal, internal or external to the relationship, including peer regulation, trusted third-actor, contract and mediation structure (Assens and Coleno, 2014).

By exploring regulation mechanisms external to relationships, the literature on coopetition differs from the above-mentioned studies in so far as a third-actor (association, union, client, local institution, etc.) can play a decisive role in terms of coordination and regulation, separating the antagonistic interests of the individuals involved in the cooperative and competitive relations (Bengtsson and Kock, 2000; Cannatelli and Antoldi, 2012). The latter may also take part in conflict resolution between partners as a potential mediator that can influence cooperation (Yami et al., 2010). Their neutrality, independence (Assens, 2011) and 
legitimacy (Dari, 2010) are crucial to the partners. For Fernandez et al. (2014), the third-actor plays a critical and ambiguous role, encouraging competition between partners, fostering cooperation and managing conflict. As network facilitator, a third party can also facilitate the process of trust development within partners (Cannatelli and Antoldi, 2012).

This approach involving a third-actor is all the more interesting since, according to Gulati (1998), inter-organizational relations should not only be looked upon in terms of relational embeddedness, which captures the links between partners, but also in terms of structural embeddedness, which focuses on their position within a broader net of actors (see above). In a context of coopetition, the intervention of a third-actor between two entities that fear one another and do not cooperate is even more understandable. More precisely, such intermediation between two non-cooperating actors can be viewed as bridging a structural gap, according to Burt (1992). Lastly, the third-actor is part of the institutional environment; consequently, its action can be analyzed through the lens of institutional embeddedness (Zukin and DiMaggio, 1990).

The fields of strategic alliances and coopetition both contribute to our understanding of dyadic and asymmetric inter-cluster relations, leading to the following question: "What are the challenges to developing a productive coopetitive inter-cluster relationship in a context of asymmetry, and what are the trust-generating mechanisms needed to overcome these challenges?"

Methodology

Choice of the two cases studied 
In July 2005, the Regional Council of Nouvelle-Aquitaine (RCA) and the InterProfessional Committee of Bordeaux Wines (CIVB) envisaged the creation of a w\&v CC, called Inno'vin. On July $5^{\text {th }} 2007$, the application was rejected by the French government. The idea of creating a wine cluster in Nouvelle-Aquitaine continued to flourish however, and Inno'vin was finally recognized as a 'grape of firms ${ }^{\prime 5}$ on 21 January 2011 . The w\&v industry has already been the subject of research on the theme of coopetition in the specific context of clusters (Dana and Granata, 2013). The fragmented nature of this industry offers indeed an interesting sector of study, with competing companies that are geographically close, and institutional governance of innovation (pooling of resources, coordination, project initiation, etc.) that can foster a cooperative dynamic between rival firms. Indeed, collaborative strategies involving individual members (that is SMEs) outside the cluster are pretty rare in this industry.

Our study thus focused qualitatively on Inno'vin's relations with:

- the LR cluster, in the Occitanie region, which obtained the CC label in 2005 and specialises in w\&v, fruit and vegetables. It was one of 14 (out of 71) clusters considered as "low performers" in the 2012 governmental evaluation.

- the MPA cluster, which became a CC in the food and agricultural sector in the Occitanie region in 2007. MPA is involved in "eight agro-chains of excellence" (duck foie gras, strawberries, corn, lamb and mutton, potato, soya, sunflower, w\&v) and was in the top 20 (of 71) clusters considered as "high performers" by the 2012 evaluation. The same year, MPA extended its activities to Nouvelle-Aquitaine.

In France, there is clear asymmetry between CCs and 'grapes' in terms of: budgets, members, management teams, recognition, access to funding, etc. Moreover, we can consider that all three clusters belong to a "competitive market" - in the words of one of the directors -

\footnotetext{
5 This is a national recognition which enabled clusters to benefit from financial support worth 200,000 euros for three years.
} 
as they continually struggle to find new members, projects and funding. Nevertheless, these clusters periodically cooperate in a more or less spontaneous way. In other words, we are dealing here with coopetitive relations.

\section{Data collection and analysis}

The time variable is crucial for analyzing coopetitive relations (Dana and Granata, 2013). The research is thus based on five distinctive data collection periods $(2010,2012,2014$, 2016 and 2017). More precisely, we conducted 45 interviews of $1 \mathrm{~h} 10$ each, with the three clusters' management teams, cluster members, state officials (for example: RCA, ADI Aquitaine Development Innovation), representatives from the different institutional structures in the w\&v industry ${ }^{6}$ (for example: CIVB, ISVV - W\&V Science Institute, IFV - French Institute for W\&V, INRA - National Institute for Agronomic Research, W\&V Department of the Chamber of Agriculture of Gironde), a consultant in charge of the CC's evaluation, interclustering specialists, etc. (See Appendix 1).

More than twenty press articles and documents issued by the ADI agency and the RCA (reports, PowerPoint presentations, interclustering studies, press releases, etc.) were also used to complete the interviews. One of the declared ambitions of ADI is indeed to facilitate and foster an inter-cluster dynamic in the region. To this end, it organises an annual seminar called “Aquitaine Interclustering”. We attended the November 2014 seminar, which gave us an opportunity to watch a joint presentation by the directors of MPA and Inno'vin on a collaborative project selected for funding by the $\mathrm{FUI}^{7}$ in October 2014. We also used the global evaluation report of CC, published by three consulting firms in June 2012. The fifth chapter

\footnotetext{
${ }^{6}$ The w\&v 'milieu' in Bordeaux is often considered by outside observers as "very closed". The representatives from the different institutions are therefore very well informed about Inno'vin and its link with other w\&v clusters.

7 "The Inter-ministry unique fund finances $R \& D$ projects which have obtained a CC label". It supports "applied research projects dealing with product, process or service development likely to be marketed in the short or medium term" (www.competitivite.gouv.fr).
} 
deals with inter-cluster collaboration. Finally, we used a resource breakdown table from Inno'vin and also collected data from the respective websites of the three clusters (in order to identify common members for instance).

To analyse our data, we adopted the template suggested by Gioia et al. (2013). "In this approach, researchers show their analytic work through a boxes and arrows figure that identifies data extracts grouped together according to first-order codes that are then grouped into second-order themes at a higher level of abstraction." (Reay, 2014: 99). Appendix 2 shows how we progressed from 51 first-order data to nine second-order themes, and from nine secondorder themes to three aggregate second-order dimensions. In this methodology, the first-order coding is inductive, because its purpose is to faithfully restore the respondents' discourse. The data then have to be conceptualized, moving back and forth between the raw data and the literature in an abductive approach. At this stage, we mobilised the key concepts of the literature review to build our data structure (asymmetry, power, dependence, resource provision, members, government funding, trusted third-actor, contract and mediation structure, etc.). Once we had created our data structure, we coded all the empirical material. Appendix 3 thus provides examples of quotes for each second-order theme. The latter were then assembled in the final model of our study (see Figure 1), helping us to develop the outline of the empirical results.

\section{Empirical Results}

Asymmetry between Inno'vin and LR/MPA 
In France, there is " $a$ strong difference between CCs and 'grapes' [...]. A form of hierarchy exists between these two types of clusters" (Global CC evaluation report, 2012: 9798).

\section{INSERT TABLE 1 ABOUT HERE}

As Table 1 shows, there is indeed asymmetry in both dyads, but it is much stronger between Inno'vin and MPA. Conversely, the asymmetry between Inno'vin and LR tended to decrease over time due to the poor performance of LR.

\section{Relations between Inno'vin and LR}

\section{The balance between cooperation and competition}

In terms of members and funding, Inno'vin and LR appear to be potential competitors in the w\&v sector. For instance, if a company in the Nouvelle-Aquitaine region wants FUI funding and/or to expand to the Occitanie region, it may be tempted to join LR. However, competition remains limited, precisely because the two entities are in different regions. ${ }^{8}$ Moreover, Inno'vin's development team considers that if it provides its members with added value, they will remain loyal.

Concerning the 'cooperation' dimension, in 2008, the French government suggested that the poorly performing LR cluster and Inno'vin should work together. Representatives from the two clusters met several times to discuss a potential merger, but failed to reach an agreement. After that, new contacts were drawn up between LR and Inno'vin, especially after Inno'vin appointed a director in 2010. Both entities still had to acknowledge the potential interest of cultivating cooperative relations. In particular, the two teams regularly talked at professional events. However, by their own admission, “they didn't achieve much”. Very occasionally, the

\footnotetext{
${ }^{8}$ If we limit our analysis to firms, Inno'vin and LR had only three joint members on March 25th 2015.
} 
two clusters undertook some joint actions (for example: joint conferences). In May 2014, a project co-developed by Inno'vin and MPA and co-labelled by LR was also proposed in the FUI's $18^{\text {th }}$ call. This was their first real collaboration. Although very few interactions had taken place between LR and Inno'vin, the idea of a merger was revived in 2015 and very seriously considered by the two clusters in 2016. Nevertheless, it was recently abandoned by decision of the Regional Council of Nouvelle-Aquitaine.

\section{The challenges of coopetition and trust-generating mechanisms}

In $\underline{\text { Table 2 }}$, we identify all the contextual challenges in the relationship between Inno'vin and LR. Despite this challenging context, the two clusters considered a merger. This leads to the question of what incited them to trust one another.

\section{INSERT TABLE 2 ABOUT HERE}

It seems clear that mutual trust between Inno'vin and LR could not be established through a public injunction, as illustrated by the attempted "arranged marriage" in 2008 . On the contrary, trusts need to develop spontaneously over time. The first collaboration on a project, in 2014 , may be viewed as a test in this respect, since no agreement had yet been signed. The management teams thus learned to work together and developed a cordial relationship.

Furthermore, there was clearly a reduction in the asymmetry between Inno'vin and LR over time, despite the difference in status ('grape' vs. CC). Indeed, at present, LR performs badly and is losing members, and its very survival is threatened, while Inno'vin is riding a very positive dynamic. ${ }^{9}$ Therefore, if the merger had taken place, it would have been a merger of equals rather than the absorption of the 'grape' by the CC. For example, unlike 2008, Inno'vin

\footnotetext{
${ }^{9}$ A cluster can be reluctant to cooperate on specific projects with a poor-performing cluster (see Table 2), but it may find it interesting to merge with this inefficient cluster in order to pool resources, eliminate competition, expand into new territories and gain a more beneficial status (that is CC status).
} 
would have been able to impose its conditions in terms of governance, status and regional specificities.

Although it didn't come to a successful conclusion, this merger seemed to meet the current interests of the French state, which seeks to simplify and rationalize the national map of clusters. In addition, this time, the rapprochement was initiated by private companies themselves. It is therefore easier to trust a rival cluster if the management team knows it is supported by the cluster's members.

\section{Relations between Inno'vin and MPA}

\section{The balance between cooperation and competition}

In 2012, MPA extended its activities to the Nouvelle-Aquitaine region where Inno'vin is based. This situation called Inno'vin's ambitions in terms of independence and development into question. Indeed, the 'grape' was not keen on becoming an entity devoted uniquely to organizing the local ecosystem and responsible for promoting projects that would simply be taken over by the CC immediately afterwards, since Inno'vin saw MPA as a much bigger competitor in terms of members, budget, projects, funding and visibility. Inno'vin's concerns were all the greater because MPA is well-known for its "expansionist policy". Thereupon, MPA rapidly tried to solicit traditional adherents of Inno'vin, as well as companies in the w\&v sector that had not yet joined the 'grape' (for example: the main châteaux of Bordeaux). ${ }^{10}$

Consequently, the arrival of MPA in its region led Inno'vin to enter into a logic of 'differentiation' to retain its members. Since then, Inno'vin has clearly sought to position itself in comparison to MPA, although the reverse is not true. More precisely, since the 'grape' specialises in wine (which is not the case of the $\mathrm{CC}$ ), its main objective was to show its

\footnotetext{
${ }^{10}$ If we limit our analysis to firms, Inno'vin and MPA had seven members in common on March $25^{\text {th }}, 2015$.
} 
unrivalled comprehensive expertise in this specific field in order to justify its existence. By strengthening its ties with companies from the w\&v sector and thus enhancing their sense of loyalty, Inno’vin erected a protective barrier.

The competition between Inno'vin and MPA could be seen in other ways. First, Inno’vin and MPA each decided to "superbly ignore" one another for two years (2012-2013). In other words, there was no real interclustering (for example no joint events or collaborative projects). Even more, each entity automatically excluded the other from its respective actions. For instance, Inno'vin was not invited to contribute to MPA's strategic roadmap and suddenly ceased to be invited to MPA's innovation clubs. This made Inno'vin very wary. In particular, the 'grape' did not invite the $\mathrm{CC}$ management team to its different events, so its rival could not acquire new members from the w\&v sector.

However, under the leadership of the RCA, a project co-constructed by Inno'vin and MPA in May 2014, labelled jointly by MPA and LR, and approved by Inno'vin, was proposed in the FUI's 18th call. This was the first sign of cooperation between the two clusters.

\section{The challenges of coopetition and trust-generating mechanisms}

In $\underline{\text { Table 3 }}$, we identify all the contextual challenges in the relations between Inno'vin and MPA. Despite this challenging context, the two clusters put forward a joint project in 2014. It now remains to understand what led them to trust each other enough to be able to work together.

\section{INSERT TABLE 3 ABOUT HERE}

Inno'vin's director, conscious of the overlap between the two clusters, quickly suggested to the director of MPA that they formally define their respective scope of action as 
well as their procedures in terms of membership rules and joint-labelling of projects. The proposal was declined by MPA which preferred to develop projects first rather than sign partnership agreements. For MPA, collaborative projects are a way of testing the partner and learning about its behaviour. Thus, any potential formalisation only occurs as a second step. In addition, settling issues such as membership fees was not as crucial for MPA as it was for Inno'vin. Consequently, Inno'vin's management team kept a close eye on its rival, waiting for it to slip up (steal members, launch an FUI w\&v project without prior warning, etc.).

Without any spontaneous interaction between Inno'vin and MPA, the RCA decided to intervene in its guise as a financing body in order to promote synergies between them. To begin with, the latter suggested signing an agreement, but failed to persuade MPA to adopt the idea. Finally, adhering to MPA's view in 2014, the RCA suggested that Inno'vin and MPA collaborate by developing an FUI project based on their complementarities. ${ }^{11}$ Inno'vin could not really turn down the RCA's offer as the latter contributed to a third of its budget in 2014 (compared to a tenth for MPA). In addition, the RCA explicitly told the two clusters not to step on each other's toes (to optimise the use of public resources), without necessarily being very directive on this point (for example through specific rules).

The RCA also played a more informal intermediation role between the two clusters, largely thanks to its ADI agency whose unofficial goal was to make the relationship between the two management teams more fluid. This role of facilitator is generally played by all the institutional actors (for example IFV and INRA) that are members of the board of the respective clusters. Finally, some companies also asked Inno'vin to clarify its position with regard to MPA. Thus, the 'grape' could hardly continue to ignore the $\mathrm{CC}$, especially as the members

\footnotetext{
11 This project for controlled management of dissolved gas in wine, with a budget of 2.8 million euros, included five private companies and three academic partners. It was accepted by FUI in October 2014, although the French government only funds $25 \%$ of what was initially requested (1 million euros). In November 2014, Inno'vin and MPA worked on a new FUI project, which this time will benefit from a joint MPA and Inno'vin label.
} 
expected Inno'vin to act at the national or even international level (which is difficult without collaborating with a CC).

\section{Discussion}

\section{The presence of competition in interclustering}

We investigated the challenges of coopetition in the specific context of asymmetric interclustering, together with ways to overcome such challenges. While many studies support the idea that clusters can cooperate (Bathelt et al., 2004; Crespo et al., 2014; Schüssler et al., 2013), the notion that they may compete with one another is much less common. Consequently, one of our theoretical contributions is to introduce the concept of competition in the context of interclustering. Moreover, we identify the exact nature of such inter-cluster competition: the struggle to attract the same members, loyalty activities targeting current members, differentiation, setting up common interest projects without consultation, exclusion of the other cluster, mutual ignorance or communication actions.

Naturally, the diversity of knowledge bases traditionally justifies collaboration between different entities (Asheim et al., 2011), especially when these knowledge bases are complementary (Peng and Bourne, 2009). We now show, in the context of interclustering, that there may be some overlap between the knowledge bases, generating areas of friction. Accordingly, we stress that cooperation between two clusters positioned in similar fields - that is rival clusters - quickly leads to reflections on a possible merger or absorption, underpinned by the desire to rationalize the use of public money and pressure from members. A merger can indeed be regarded as a possible evolution of coopetition between competing networks, as explained by Peng and Bourne (2009). It also confirms the belief that integration can resolve the tension resulting from a coopetition situation (Chen, 2008; Fernandez et al., 2014). 
We might imagine that the situation studied here (that is clusters working in the same field, in the same or a nearby geographical territory) is very specific. However, the inter-cluster competition highlighted here is much broader than that. Let's take, for instance, the case of a project conducted through collaboration between a cluster with fundamental knowledge of a specific technology (for example: drones, laser, digital processes, etc.) and the Inno'vin cluster, which is able to turn this fundamental knowledge into practical tests in the w\&v industry (Balland et al., 2010). The two clusters thus have distinct and complementary resources. It is therefore quite appropriate for them to collaborate since both partners complement the knowledge chain (Balland et al., 2010; Peng and Bourne, 2009). However, the two clusters also have the same goal to retain the company leading the project as a member. In other words, competition is also at work here.

\section{Challenges of inter-cluster coopetition and the role of asymmetry}

Another contribution of this paper is to highlight the various challenges of inter-cluster coopetition (Table 4).

\section{INSERT TABLE 4 ABOUT HERE}

However, a static reading of this table appears insufficient. We should instead adopt a dynamic perspective, which means taking into consideration the concept of cluster lifecycle (Maskell and Kebir, 2005; Menzel and Fornhal, 2010; Ingstrup and Damgaard, 2013). For instance, during the existence phase (Maskell and Kebir, 2005), Inno'vin had no interest in merging with a poor-performing CC like LR since, at this time, Inno'vin was slowly structuring itself, had almost no activity and did not want to be dragged down. Conversely, in 2015, Inno'vin was in its expansion phase (Maskell and Kebir, 2005) and had displayed its dynamic 
potential, while LR was in a phase of stagnation (Menzel and Fornhal, 2010). Thus, Inno'vin viewed the potential merger with the low-performing $\mathrm{CC}$ as a way to grow faster and to pool resources. This example also shows that one specific factor - here, cluster performance - can have a distinct impact on coopetition according to the level of inter-cluster asymmetry. In 2008, Inno'vin worked in a very informal, even virtual way (for example: no director and no labelling committee), while LR was a CC cluster. There was indeed a status and lifecycle-related asymmetry. Consequently, the (prompted) merger between LR and Inno'vin would have resulted in absorption of the latter by the former in order to save LR. In 2016, Inno'vin felt almost equal to LR and could have impose its conditions more easily in the event of a merger. There was no performance-related asymmetry. In this respect, we show that asymmetry is a key variable in the inter-cluster coopetitive relationship. More precisely, it has a distinct impact (for example: coercive or voluntary cooperation) depending on its magnitude. This is consistent with the work of Cimon (2004) in particular, which highlights the cross development between asymmetries and the dynamics of an alliance. Beyond the fact that the magnitude of asymmetry varies over time, our study also allows us to operationalize this concept of asymmetry (Casciaro and Piskorski, 2005; Chen and Chen, 2002) in a complementary way in terms of: number of members, staff in the animation teams, funding, level of attractiveness, national/international recognition, level of performance, size of projects and level of dependence with regard to public funders.

In addition, our study investigates clusters (LR and Inno'vin) that are potentially in the last phase of their lifecycle, that is in "a decline or reinvention stage" (Ingstrup and Damgaard, 2013: 560), which are seldom studied. In its ultimate form, cooperation with competitors through mergers or absorption appears to be a way for clusters to reinvent themselves in order to avoid decline. Following Ingstrup and Damgaard (2013), we underscore a new role played by cluster facilitators in managing this stage. 


\section{Trust-generating mechanisms}

A last contribution of our article concerns the identification of trust-generating mechanisms as trust appears to be a key success factor in inter-cluster relations (Bathelt and $\mathrm{Li}$, 2014; Schüssler et al., 2013). Following the article of Cannatelli and Antoldi (2012) focusing on factors leading to trust creation (in the specific context of strategic alliances), we thus contribute to the literature by highlighting two very different views (that of Inno'vin versus that of MPA/LR) of the attitude to adopt in order to generate a climate of trust and promote cooperation in a coopetitive inter-cluster relationship:

- Signing an agreement that clarifies the relationship as early as possible so as to collaborate without fear of opportunistic behaviour by the partner-competitor. This is a strategy that aims to reduce the climate of uncertainty surrounding an inter-cluster relationship. This option of formalising actions (Dana and Granata, 2013) is linked to the transactional approach of asymmetry control (Donada and Nogatchewsky, 2006).

- Taking part in a mutual learning approach through concrete cooperation on joint projects. Strengthening collaboration (Dana and Granat, 2013) is a proactive strategy, aimed at testing the partner in the joint activity and assessing whether the latter is reliable, competent and complementary enough. It reflects the concept of learning-by-cooperating (Bureth et al., 1997), which integrates alliance dynamics (Larson, 1992; Ring and van de Ven, 1994), promoting a form of cooperation that can strengthen with time and experience, consistent with the notion of "process-based trust" (Zucker, 1986). This learning-by-cooperating approach echoes the tit-fortat approach described by Axelrod (1984) in game theory. Interclustering indeed appears as an ongoing game in which the cluster adapts its stance (cooperation versus non-cooperation) to the behaviour of the rival cluster in the preceding period. 
Like Donada and Nogatchewsky (2006), however, we show that the two approaches can be combined. For instance, effective collaboration (for example, in an FUI project) can lead to a better understanding of the partner-cluster, and consequently to more formalised collaboration based on concrete information and/or collaboration procedures. In other words, the contract can potentially be completed ex post (Hart and Moore, 1990). Contrariwise, unlike Donada and Nogatchewsky (2006), our paper does not oppose contractual relationships and trust. Instead, we highlight two separate, internal trust-generating mechanisms, because a contract can also generate trust. Furthermore, we establish that the learning-by-cooperating approach does not necessarily rely on pre-existing relational proximity. Moreover, beyond the transactional and relational approaches, we identify a third process that could be called the "observation round". As illustrated by the Inno'vin/MPA case, clusters do not sign anything and do not cooperate on joint projects during this time, but are nonetheless monitoring and gauging each other closely. Furthermore, we also show that the trade-off between formal control and informal control does not simply correlate with the scope of the perceived asymmetries, as Donada and Nogatchewsky (2006) claim. Perceiving strong asymmetry, synonymous with risk, Inno'vin suggested a formal solution by way of a charter, but in the end an informal solution was imposed by MPA with the support of the RCA. This seems to indicate that a trade-off occurs involving a third-actor within a relations system, and not only at the level of the dyad.

Nevertheless, this type of interclustering without any initial contract is possible only because a third-actor - here, a local institution - monitors and regulates the coopetitive relationship (Cannatelli and Antoldi, 2012; Fernandez et al., 2014), making sure that neither cluster cheats in the dilemma between cooperation and non-cooperation (Axelrod, 1984; Fink et al., 2010). To some extent, this type of public intervention helps to create a relationship of mutual trust between the two clusters, echoing the concept of "institutional-based trust" (Zucker, 1986). In other words, because of the competitive context, trust does not exist ex ante, 
but the public third-actor promotes and drives the cooperation, enabling the two entities to get to know and progressively trust one another.

This regulation by a third-actor is all the more natural in that potential competition between the potential partners prevents any cooperative relationship. In other words, the competitive context leads to a structural hole (Burt, 1992) between actors whose resources can complement each other's. Consequently, the third-actor bridges the structural hole, following its own interest in order to ultimately obtain more FUI funding. In the end, the intervention of the third-actor does not appear to balance the asymmetry, as suggested by the alliance literature, but contributes to the balance between cooperation and competition.

On this point, the literature on coopetition postulates that coopetition is positive coopetition is indeed meant to "enlarge the pie" (Brandenburger and Nalebuff, 1996; Dana and Granata, 2013) - and must be regulated. In the specific context of interclustering, we show that regulation - by both public actors and private members - essentially aims at eliminating competition (definition of the scope of actions, merger, etc.). In other words, contrary to Bengtsson and Kock (2014), coopetition in the context of interclustering needs to be described in accordance with a single continuum, with cooperation and competition at each extreme. Indeed, when the competition is reduced in intensity, it improves de facto the conditions for cooperation. This can be explained by the fact that the fields of competition and cooperation are not separate (Peng and Bourne, 2009). In short, we put forward the argument that competitive situations should be avoided in interclustering (waste of public money, source of complexity for members, barrier to development for clusters, etc.). Our result thus counters the traditional view. For instance, in an intra-cluster context, we consider that "competition acts as a vital driver for development and continuous improvements" (Ingstrup and Damgaard, 2013: 561) and is therefore "indispensable" (Dana and Granata, 2013: 429). 
In our article, local institutions do not appear to play the role of a neutral mediator (Assens, 2011; Cannatelli and Antoldi, 2012). Indeed, according to Bengtsson and Kock (2000), the RCA does not seem to try to separate antagonistic interests. The CC dictates the approach to be followed (that is starting by building an FUI project instead of signing an agreement) because the local institution depends on the FUI resources the CC can obtain in a context of decreasing public funding. Thanks to transitivity, the local institution then demands that the smaller cluster - itself dependent on the local institution - conforms to the more informal approach of learning-by-cooperating (Bureth et al., 1997) dictated by the CC.

In other words, we illustrate here a chain of asymmetric relations which play a key role in regulating coopetition. By nature, an analysis of inter-cluster relations in terms of a coopetitive system (Yami et al., 2010) rather than dyads seems highly appropriate. Moreover, it is debatable whether this chain of asymmetric relations ultimately leads to fair 'pie-sharing' (Brandenburger and Nalebuff, 1996). It seems, on the contrary, that a high-performance CC benefits from greater structural embeddedness and from more favorable institutional embeddedness (Zukin and DiMaggio, 1990) when it comes to defining the rules of coopetition.

Our study thus highlights a formal mediation process by public actors. In particular, as financing bodies, local institutions can enforce and then regulate coopetitive relations within the territory. These third-actors that control access to external resources help to balance the cooperation/competition dichotomy, preventing avoidance or estrangement in particular (Bengtsson et al., 2010; Bengtsson and Kock, 2014). In a more informal way, "secant marginals" (Crozier and Friedberg, 1977) also ensure the interface between the rival clusters (Assens and Coleno, 2014), especially in terms of spread of information and intermediation, notably as members of the respective cluster boards, and by trying to reconcile their opposing perspectives. 


\section{Conclusion}

Our paper studies the challenges to developing a productive coopetitive inter-cluster relationship, in a context of asymmetry, and the trust-generating mechanisms needed to overcome these challenges. To this end, we analysed two types of inter-cluster relationship positioned in the same field (w\&v industry), with the clusters located in the same or a nearby territory. Our findings highlight the importance of competition in the context of interclustering, a reality that was previously ignored. Moreover, we identify three categories of inter-cluster coopetition challenges: competition drivers (overlapping missions, search for recognition, etc.), barriers to cooperation (different strategic visions, phase shift in the lifecycle, etc.) and cooperation drivers (complementarities, feeling of win-win, etc.). On this point, we emphasise the importance of a dynamic reading in order to interpret the impact of each variable on intercluster coopetition, while stressing the role of inter-cluster asymmetry. Finally, we extend the existing literature on trust-generating mechanisms.

At managerial level, one of our contributions is to help cluster facilitators to know when it is productive to cooperate with a rival cluster or not and how to operate in practice, taking existing challenges into account. It appears, in this case, that the ideal timing for cooperation in a context of inter-cluster rivalry is significantly linked to the prior intervention of public and private actors. We also suggest to third-party actors the most appropriate timing to regulate inter-cluster coopetition. In addition, we identify the necessity of such an intervention since the inter-cluster coopetition process seems unable to provide internal regulation.

However, the study has certain limitations. In fact, our study only concerns French clusters. This naturally leads us to investigate 'institutional' clusters, organized according to national and regional public policies, which explains and justifies the intervention of these public actors. This specific context is at least partially behind the asymmetry noted between the 
clusters, whether they benefit from the $\mathrm{CC}$ label or not, and their resource-dependence on public actors. In this respect, we agree with Peng and Bourne (2009) who recommend investigating the contingency factors that simultaneously influence cooperation and competition: the institutional context indeed appears to be an important contingency variable. This is a major limitation in the generalization of our findings at international level. Consequently, our research could benefit from a study of relations between a French and a foreign cluster within the same domain in order to neutralize the effects of public interventions at national or regional level. 


\section{References}

Amisse, S., Hussler C., Muller P. and Rondé P. 2011. "Do birds of a feather flock together? Proximities and interclusters network." European Regional Science Association Conference, Barcelona.

Asheim, B., Boschma R. and Cooke P. 2011. "Constructing regional advantage: Platform policies based on related variety and differentiated knowledge bases." Regional Studies 45(7), 893-904.

Assens, C. 2011. "Les comportements opportunistes dans la coopétition : Le cas de l'Union nationale des coopératives d'élevage et d'insémination animale." Revue internationale de l'économie sociale 322, 80-95.

Assens, C. and Coléno F. 2014. "How to manage free riders in a network of competitors: the case of animal genetic selection industry in France." Journal on Chain and Network Science 14(2), 129-135.

Axelrod, R. 1984. The evolution of cooperation. New York: Basic books.

Balland, P.-A., Suire R. and Vicente J. 2010. "How do Clusters/Pipelines and Core/Periphery Structures Work Together in Knowledge Processes?" Evolutionary Economic Geography Utrecht University.

Bathelt, H. and Li P.F. 2014. "Global cluster networks - foreign direct investment flows from Canada to China." Journal of Economic Geography 14(1), 45-71.

Bathelt, H., Malmberg A. and Maskell P. 2004. "Clusters and knowledge: local buzz, global pipelines and the process of knowledge creation." Progress in Human Geography 28(1), $31-56$

Bengtsson, M., Eriksson J. and Wincent J. 2010. "Co-opetition dynamics-an outline for further inquiry." Competitiveness Review 20(2), 194-214.

Bengtsson, M. and Kock S. 2000. "Coopetition in Business Networks - to Cooperate and Compete Simultaneously." Industrial Marketing Management 29(5), 411-426.

Bengtsson, M. and Kock S. 2014. "Coopetition-Quo vadis? Past accomplishments and future challenges." Industrial Marketing Management 43(2), 180-188.

Brandenburger, A. and Nalebuff B. 1996. Co-opetition, New York: Doubleday.

Bureth, A., Wolff S. and Zanfei A. 1997. "The two faces of learning by cooperating: the evolution and stability of inter-firm agreements in the European electronics industry." Journal of Economic Behavior \& Organization 32(4), 519-537.

Burt, R. S. 1992. Structural Holes: The Social Structure of Competition. Harvard University Press, Cambridge, MA.

Cannatelli, B. and Antoldi F. 2012. "The Role of Network Facilitators in Fostering Trust within Strategic Alliances: A Longitudinal Case Study." Journal of Small Business \& Entrepreneurship 25(1), 19-34.

Casciaro, T. and Piskorski M. 2005. "Power imbalance, mutual dependence, and constraint absorption: A closer look at resource dependence theory." Administrative Science Quarterly 50(2), 167-199.

Chen, M.J. 2008. "Reconceptualizing the competition-cooperation relationship: A transparadox perspective." Journal of Management Inquiry 17(4), 288-305.

Chen, H. and Chen T.J. 2002. "Asymmetric strategic alliances: A network view." Journal of Business Research 55(12), 1007-1013.

Cimon, Y. 2004. "Knowledge-related asymmetries in strategic alliances." Journal of Knowledge Management 8(3), 17-30.

Crespo, J., Suire R. and Vicente J. 2014. "Lock-in or lock-out? How structural properties of knowledge networks affect regional resilience." Journal of Economic Geography 14(1), 199-219.

Crozier, M. and Friedberg E. 1977. L'acteur et le système. Paris: Le Seuil. 
Dana, L.-P. and Granata J. 2013. "Évolution de la coopétition dans un cluster : le cas de Waipara dans le secteur du vin." Journal of Small Business \& Entrepreneurship 26(4), 429-442.

Dari, L. 2010. "Third Party Stakeholders: The Key To Coopetition Strategies In The ReadyTo-Wear Sector?" International Review of Business Research Papers 6(1), 597-618.

Das, T.K. and Teng B.S. 2001. "A risk perception model of alliance structuring." Journal of International Management 7(1), 1-29.

Delerue, H. 2010. "Modes de contrôle et partage des droits de la propriété intellectuelle : Le cas des alliances de R\&D." Journal of Small Business and Entrepreneurship 23(1), $117-$ 131.

Donada, C. and Nogatchewsky G. 2006. "Vassal or lord buyers: How to exert management control in asymmetric interfirm transactional relationships?" Management Accounting Research 17(3), 259-287.

Doz, Y. and Hamel G. 1998. Alliance advantage: The art of creating value through partnering. MA: Harvard Business Press.

Dussauge, P. and Garrette B. 1999. Cooperative Strategy: Competing Successfully Through Strategic Alliances, Chichester: Wiley.

Fernandez, A.-S., Le Roy F. and Gnyawali D. 2014. "Sources and management of tension in coopetition case evidence from telecommunications satellites manufacturing in Europe." Industrial Marketing Management 43(2), 222-235.

Fink M., Roessi D. and Gundolf K. 2010. "Coopération, confiance et réussite - Considérations théoriques et résultats empiriques." Journal of Small Business \& Entrepreneurship 23(2), 271-285.

Gioia, D., Corley K. and Hamilton A. 2013. "Seeking Qualitative Rigor in Inductive Research: Notes on the Gioia Methodology" Organizational Research Methods 16(1), 15-31.

Granovetter, M. 1985. "Economic action and social structure: The problem of embeddedness." American Journal of Sociology 91(3), 481-510.

Granovetter, M. 1992. "Problems of explanation in economic sociology." In N. Nohria and R. Eccles (eds.), Networks and Organizations: Structure, Form and Action. Harvard Business School Press, Boston, MA, 25-56.

Gulati, R. 1998. "Alliances and networks." Strategic Management Journal 19, 293-317.

Hamel, G., Doz Y. and Prahalad C.K. 1989. "Collaborate with Your Competitors - and Win." Harvard Business Review 67(1), 133-139.

Hart, O. and Moore J. 1990. "Property Rights and the Nature of the Firm." Journal of political economy 98(6), 1119-1158.

Ingstrup, M. and Damgaard T. 2013. "Cluster Facilitation from a Cluster Life Cycle Perspective." European Planning Studies 21(4), 556-574.

Larson, A. 1992. "Network dyads in entrepreneurial settings: A study of the governance of exchange relationships." Administrative Science Quarterly 37(1), 76-104.

Lundequist, P. and Power D. 2002. "Putting Porter into practice? Practices of regional cluster building: Evidence from Sweden." European Planning Studies 10(6), 687-704.

Maskell, P. and Kebir L. 2005. "What qualifies as a cluster theory." DRUID Conference, Copenhagen.

Menzel, M.-P. and Fornahl D. 2010. "Cluster life cycles - dimensions and rationales of cluster evolution." Industrial and Corporate Change 19(1), 205-238.

Mesquita, L. 2007. "Starting cover when the bickering never ends: Rebuilding aggregate trust among clustered firms through trust facilitators." Academy of Management Review 32(1), 72-91.

Peng, T.J. and Bourne M. 2009. "The Coexistence of Competition and Cooperation between Networks: Implications from Two Taiwanese Healthcare Networks." British Journal of Management 20(3), 377-400. 
Porter, M. 1998. "Clusters and the new economics of competition." Harvard Business Review 76(6), 77-90.

Reay, T. 2014. "Publishing qualitative research." Family Business Review 27(2), 95-102.

Ring, P. and Van de Ven A. 1994. "Developmental processes of cooperative interorganizational relationships." Academy of Management Review 19(1), 90-118.

Schüßler, E., Decker C. and Lerch F. 2013. "Networks of Clusters: A Governance Perspective." Industry and Innovation 20(4), 357-377.

Teigland, R. and Lindqvist G. 2007. "Seeing Eye-to-eye: How do Public and Private Sector Views of a Biotech Cluster and its Cluster Initiative Differ?" European Planning Studies 15(6), 767-786.

Thomason, S. and Kiernan D. 2013. "Several determinants of successful coopetition in small business." Journal of Small Business \& Entrepreneurship 26(1), 15-28.

Vidot-Delerue, H. and Simon E. 2005. "Confiance, contrat et degré d'asymétrie dans les relations d'alliance." Management International 10(1), 51-62.

Wang, C.H. 2011. "The moderating role of power asymmetry on the relationships between alliance and innovative performance in the high-tech industry." Technological Forecasting and Social Change 78(7), 1268-1279.

Yami, S., Castaldo S., Dagnino B., Le Roy F. and Czakon W. 2010. "Introduction: coopetition strategies: towars a new form of inter-organizational dynamics." In Yami S., Castaldo, S., Dagnino B., Le Roy F. (Eds) Coopetition: winning strategies for the 21st century, Cheltenham: Edward Elgar Publishing, 1-18.

Zucker, L. 1986. "Production of trust: institutional sources of economic structure, 1840-1920." Research in Organization Behaviour 8, 53-11.

Zukin, S. and P. DiMaggio. 1990. Structures of Capital: The Social Organization of the Economy. Cambridge University Press, Cambridge, MA. 
TABLE 1: ASYMMETRY BETWEEN INNO'VIN AND LR/MPA

\begin{tabular}{|l|l|}
\hline Criteria & Inno'vin vs. LR/MPA \\
\hline Cluster members & $\begin{array}{l}\text { At the end of the first semester 2015, Inno'vin had 104 members against 142 } \\
\text { for LR and 332 for MPA. However, membership continued to rise at Inno'vin } \\
\text { and MPA, while it fell at LR. }\end{array}$ \\
\hline Cluster management teams & $\begin{array}{l}\text { At the end of the first semester 2015, there were two individuals in Inno'vin's } \\
\text { management team against five for LR and 12 for MPA. This made it harder } \\
\text { for Inno'vin to engage in active partnerships. Inno'vin later recruited a } 3^{\text {rd }} \\
\text { person. }\end{array}$ \\
\hline Funding/Attractiveness & $\begin{array}{l}\text { In France, CCs and 'grapes' do not have the same access to state subsidies. } \\
\text { The FUI only finances R\&D projects which have obtained a CC label. A CC } \\
\text { is therefore more attractive to a region than a 'grape', especially if it is expert } \\
\text { at accessing FUI funding (like MPA). }\end{array}$ \\
\hline Recognition/Performance & $\begin{array}{l}\text { Thanks to its label, a CC enjoys greater recognition nationally and } \\
\text { internationally. Moreover, MPA was considered as a "high performer" in the } \\
\text { 2012 evaluation. Conversely, the LR cluster is seen as a "low performer". }\end{array}$ \\
\hline Projects & $\begin{array}{l}\text { The projects carried out by 'grapes' are often of lesser magnitude than in a } \\
\text { CC. Generally, 'grapes' have to rely on a CC to undertake larger projects. }\end{array}$ \\
\hline funders & $\begin{array}{l}\text { Financial support from public authorities is greater for CCs. Moreover, a CC } \\
\text { that has many private members (like MPA) will be more independent in its } \\
\text { decision-making than a 'grape'. }\end{array}$ \\
\hline
\end{tabular}




\section{TABLE 2: COOPETITION CHALLENGES IN THE RELATIONS BETWEEN INNO'VIN AND LR}

\begin{tabular}{|c|c|}
\hline Competition drivers & Case study \\
\hline $\begin{array}{l}\text { Both clusters aim to be visible and recognized in a } \\
\text { context where resources are scarce. }\end{array}$ & $\begin{array}{l}\text { Clusters are evaluated based on the number of projects } \\
\text { completed. Inno'vin and LR thus seek to expand in } \\
\text { their respective regions. }\end{array}$ \\
\hline $\begin{array}{l}\text { Both clusters are involved in the w\&v sector and are } \\
\text { interested in the same members, funding and projects. }\end{array}$ & $\begin{array}{l}\text { LR specialises in w\&v, cereals, fruit and vegetables, } \\
\text { while Inno'vin specialises in w\&v only. Therefore, } \\
\text { both clusters are likely to attract the same companies in } \\
\text { the w\&v industry and to undertake similar projects. }\end{array}$ \\
\hline Both regions have historic rivalry. & $\begin{array}{l}\text { In w\&v research, the Nouvelle-Aquitaine and } \\
\text { Occitanie regions are strong rivals. We can talk here } \\
\text { about jealousy (for example hegemony of Bordeaux } \\
\text { wines } v s \text {. renown of Montpellier higher education and } \\
\text { research institute - and greater financial support from } \\
\text { INRA). }\end{array}$ \\
\hline Barriers to cooperation & Case study \\
\hline $\begin{array}{l}\text { A cluster does not want to cooperate with a poor- } \\
\text { performing cluster with an uncertain future. }\end{array}$ & $\begin{array}{l}\text { After phase one of the CC policy (2005-2008), the LR } \\
\text { cluster ranked among the } 13 \text { (of } 71 \text { ) clusters which } \\
\text { could "benefit from a major overhaul" (worst } \\
\text { category). The cluster's survival was then clearly under } \\
\text { threat and it was not an attractive potential partner. }\end{array}$ \\
\hline $\begin{array}{l}\text { Clusters do not cooperate if they have different } \\
\text { strategic visions. }\end{array}$ & $\begin{array}{l}\text { In } 2008 \text {, representatives from the two clusters met } \\
\text { several times to discuss a potential merger. However, } \\
\text { their opposing strategic visions (supply strategy vs. } \\
\text { demand strategy) appeared irreconcilable. }\end{array}$ \\
\hline $\begin{array}{l}\text { Clusters do not cooperate if there is disagreement in } \\
\text { terms of governance. }\end{array}$ & $\begin{array}{l}\text { When representatives from the two clusters met in } \\
2008 \text {, no agreement could be reached in terms of } \\
\text { common governance as each cluster wanted to retain } \\
\text { its leadership and preserve its own interests. }\end{array}$ \\
\hline $\begin{array}{l}\text { Clusters do not cooperate if their lifecycles are out of } \\
\text { sync. }\end{array}$ & $\begin{array}{l}\text { When the merger was considered, Inno'vin was still is } \\
\text { its emerging phase. Then, when Inno'vin had } \\
\text { completed its structuring phase, LR was undergoing } \\
\text { reorganization. }\end{array}$ \\
\hline $\begin{array}{l}\text { Management team instability prevents strong } \\
\text { relationships from being built over time }\end{array}$ & $\begin{array}{l}\text { The LR management team has changed several times } \\
\text { due to the CC's poor performance. Consequently, the } \\
\text { directors of the two entities lacked relational } \\
\text { proximity. For instance, each director appeared to feel } \\
\text { that they had made the first move and had met with } \\
\text { resistance from their counterpart. }\end{array}$ \\
\hline $\begin{array}{l}\text { Clusters do not cooperate if the management teams of } \\
\text { each cluster lack geographical proximity. }\end{array}$ & $\begin{array}{l}\text { Bordeaux and Montpellier are almost } 500 \mathrm{~km} \text { apart. } \\
\text { Thus, the two management teams did not see each other } \\
\text { very often and found it hard to organise joint events. }\end{array}$ \\
\hline
\end{tabular}




\begin{tabular}{|l|l|}
\hline Cooperation drivers & Case study \\
\hline Clusters cooperate if they have common issues. & $\begin{array}{l}\text { Since the two clusters are in the w\&v sector, they face } \\
\text { the same challenges and the same demands, especially } \\
\text { in terms of R\&D. }\end{array}$ \\
\hline Clusters cooperate if they are complementary. & $\begin{array}{l}\text { In 2008, the idea of pooling resources appeared } \\
\text { interesting for complementary and neighbouring } \\
\text { clusters, with one (LR) seeking to adapt its wines to the } \\
\text { customers' tastes, while the other (Inno'vin) wanted to } \\
\text { improve its wine quality. }\end{array}$ \\
\hline $\begin{array}{l}\text { Clusters cooperate if the "size effect" offers them } \\
\text { greater visibility. }\end{array}$ & $\begin{array}{l}\text { Occitanie and Nouvelle-Aquitaine are the two biggest } \\
\text { wine-producing French regions. A rapprochement } \\
\text { therefore gives greater international visibility. }\end{array}$ \\
\hline $\begin{array}{l}\text { Clusters cooperate if the management teams feel that it } \\
\text { is a win-win situation. }\end{array}$ & $\begin{array}{l}\text { In 2015, the rapprochement was seen as mutually } \\
\text { beneficial since the poor-performing LR cluster can } \\
\text { benefit from Inno'vin's dynamics, while the Inno'vin } \\
\text { 'grape' can gain access to FUI funding. }\end{array}$ \\
\hline $\begin{array}{l}\text { Clusters cooperate if members are unsatisfied with the } \\
\text { cluster map. }\end{array}$ & $\begin{array}{l}\text { W\&V companies pay high fees for multiple } \\
\text { memberships but they do not want to have to pay twice } \\
\text { and would like more clarity. }\end{array}$ \\
\hline
\end{tabular}




\section{TABLE 3: COOPETITION CHALLENGES IN RELATIONS BETWEEN INNO'VIN AND MPA}

\begin{tabular}{|c|c|}
\hline Competition drivers & Case study \\
\hline $\begin{array}{l}\text { Both clusters aim to be visible and recognized in a } \\
\text { context of scarce resources. }\end{array}$ & $\begin{array}{l}\text { MPA is ranked as a "high performing" CC and } \\
\text { ambitions to become the European leader in the food } \\
\text { and agricultural sector. Conquering the w\&v industry } \\
\text { around Bordeaux (highly renowned internationally), } \\
\text { can help to achieve this goal. The CC is in a } \\
\text { development strategy and is very attractive for the } \\
\text { Nouvelle-Aquitaine region, which targets FUI funding } \\
\text { for its w\&v industry. Faced with this "giant", the } \\
\text { 'grape' - which is more dependent on public resources } \\
\text { - struggles to remain visible, survive and expand. }\end{array}$ \\
\hline $\begin{array}{l}\text { Both clusters are involved in the w\&v sector and are } \\
\text { interested in the same members, funding and projects. }\end{array}$ & $\begin{array}{l}\text { Inno'vin specialises in w\&v, while MPA handles duck } \\
\text { foie gras, strawberries, corn, sheep meat, potato, soya, } \\
\text { sunflower, w\&v. There is a partial overlap and both } \\
\text { clusters are liable to attract the same w\&v companies } \\
\text { and to undertake similar projects. }\end{array}$ \\
\hline $\begin{array}{l}\text { The presence of two clusters, working in the same field } \\
\text { in a common territory, enhances competition. }\end{array}$ & $\begin{array}{l}\text { "When CCs and 'grapes' cover more or less the same } \\
\text { sector in the same territory, there may be competition } \\
\text { to attract members that do not want to pay two } \\
\text { membership fees." (Global CC evaluation report, 2012: } \\
\text { 13). }\end{array}$ \\
\hline Barriers to cooperation & Case study \\
\hline $\begin{array}{l}\text { Clusters do not cooperate if they have different } \\
\text { strategic visions. }\end{array}$ & $\begin{array}{l}\text { MPA does not reason by sector, but technologically } \\
\text { and transversely. Its management team defends the } \\
\text { concept of "food chains", and wine is not a priority, } \\
\text { while the w\&v industry is the single focus of Inno'vin. }\end{array}$ \\
\hline $\begin{array}{l}\text { Clusters do not cooperate if they feel there is a risk of } \\
\text { losing their identity. }\end{array}$ & $\begin{array}{l}\text { For Inno'vin, the merger risks creating a situation } \\
\text { where } w \& v \text { are lost among all the other areas covered } \\
\text { by MPA; the cluster would lost its " } w \& v \text { " identity. }\end{array}$ \\
\hline $\begin{array}{l}\text { Clusters do not cooperate if there is disagreement in } \\
\text { terms of governance, which is the case if one of the two } \\
\text { clusters feels superior to the other. }\end{array}$ & $\begin{array}{l}\text { Because of its performance, the MPA cluster has a } \\
\text { sense of superiority. Consequently, if a "giant" like } \\
\text { MPA cooperates with a "dwarf" like Inno'vin, the } \\
\text { former is inclined to impose its operating rules. }\end{array}$ \\
\hline $\begin{array}{l}\text { Clusters do not cooperate if there is a lack of relational } \\
\text { proximity. }\end{array}$ & $\begin{array}{l}\text { Some interviewees mentioned "tense relations" } \\
\text { between the directors. There was mutual distrust. }\end{array}$ \\
\hline $\begin{array}{l}\text { Clusters do not cooperate if they fear the consequences } \\
\text { of such collaboration. }\end{array}$ & $\begin{array}{l}\text { Inno'vin fears that MPA will take advantage of all its } \\
\text { work (coordinating the network of firms in the w\&v } \\
\text { industry) in order to set up projects improving its own } \\
\text { visibility (at the expense of Inno'vin). Inno'vin's } \\
\text { survival would thus be threatened (absorption or } \\
\text { extinction). }\end{array}$ \\
\hline Cooperation drivers & Case study \\
\hline Clusters cooperate if they are complementary. & $\begin{array}{l}\text { Inno'vin has real w\&v expertise, and has developed an } \\
\text { extensive regional network. MPA is expert in setting }\end{array}$ \\
\hline
\end{tabular}




\begin{tabular}{|l|l|}
\hline & $\begin{array}{l}\text { up projects and very competent in accessing FUI } \\
\text { funding. }\end{array}$ \\
\hline $\begin{array}{l}\text { Clusters cooperate if the management teams feel it is a } \\
\text { win-win situation. }\end{array}$ & $\begin{array}{l}\text { Thanks to cooperation, Inno'vin can access FUI } \\
\text { funding (restricted to CCs), while MPA increases its } \\
\text { chances of developing successful w\&v projects. }\end{array}$ \\
\hline $\begin{array}{l}\text { Clusters cooperate if members are unsatisfied with the } \\
\text { cluster map. }\end{array}$ & $\begin{array}{l}\text { The two clusters deal with w\&v within the same } \\
\text { region. For companies, this is illogical. They do not } \\
\text { want to pay twice and would like a "one-stop shop". }\end{array}$ \\
\hline
\end{tabular}


TABLE 4: CHALLENGES OF INTER-CLUSTER COOPETITION

\begin{tabular}{|l|l|l|}
\hline Competition drivers & Barriers to cooperation & Cooperation drivers \\
\hline Search for recognition & Poor performance & Common issues \\
Overlapping missions & Differtainty about the future & Complementarities \\
Belonging to the same territory & Risk of losing identity & Perspective of greater visibility \\
Scarcity of financial resources & Impression of win-win situation \\
Historic rivalry between territories & Disagreement on governance & Strong and mature relationships \\
& Phase shift in the lifecycles & Member dissatisfaction \\
& Instability of management teams & \\
& Lack of relational proximity & \\
& Lack of geographic proximity & \\
& Sense of superiority/inferiority & \\
& Fear & \\
\hline
\end{tabular}

